Casas, L., Espinosa, A., Pekkanen, J., Asikainen, A., Borràs-Santos, A., Jacobs, J., Krop, E., Täubel, M., Hyvärinen, A., Heederik, D., Zock, J.P. School attendance and daily respiratory symptoms in children: influence of moisture damage. Indoor Air: 2016, 27(2), 303-310

\begin{tabular}{|l|l|}
\hline $\begin{array}{l}\text { Postprint } \\
\text { Version }\end{array}$ & 1.0 \\
\hline
\end{tabular}

Journal website http://onlinelibrary.wiley.com/doi/10.1111/ina.12311/abstract;jsessionid=336D424 39D5FB9B38428E5B7004FE2DF.f02t04

Pubmed link http://www.ncbi.nlm.nih.gov/pubmed/27224645

DOI 10.1111/ina.12311

This is a NIVEL certified Post Print, more info at http://www.nivel.eu

\title{
School attendance and daily respiratory symptoms in children: influence of moisture damage
}

\author{
LIDIA CASAS, ${ }^{\mathrm{A}, \mathrm{B}, \mathrm{C}, \mathrm{D}}$ ANA ESPINOSA, ${ }^{\mathrm{B}, \mathrm{C}, \mathrm{D}, \mathrm{E}}$ JUHA PEKKANEN, ${ }^{\mathrm{F}, \mathrm{G}}$ ARJA ASIKAINEN, ${ }^{\mathrm{F}}$ ALÍCIA \\ BORRÀs-SANTOS, ${ }^{\mathrm{B}, \mathrm{C}, \mathrm{D}, \mathrm{H}} \mathrm{JOSÉ}$ JACOBS, ${ }^{\mathrm{I}}$ ESMERALDA KROP, ${ }^{\mathrm{I}}$ MARTIN TÄUBEL, ${ }^{\mathrm{F}}$ ANNE \\ HYVÄRINEN, ${ }^{\mathrm{F}}$ DICK HEEDERIK, ${ }^{\mathrm{I}}$ AND JAN- PAUL ZOCK. ${ }^{\mathrm{B,C}, \mathrm{D}, \mathrm{J}}$
}

aDeppartment of Public Health and Primary Care - Centre for Environment and Health KU Leuven, Leuven, Herestraat 49, 3000 Leuven, Belgium bISGlobal, Centre for Research in Environmental Epidemiology (CREAL), Dr Aiguader 88, 08003 Barcelona, Spain.

cUniversity Pompeu Fabra (UPF), Plaça de la Mercè, 10-12, 08002 Barcelona, Spain. dCIBER Epidemiología y Salud Pública (CIBERESP), Av. Monforte de Lemos, 3-5. Pabellón 11. Planta 0 28029, Madrid, Spain.

eHosptal del Mar Medical Research Institute (IMIM), Dr Aiguader 88, 08003 Barcelona, Spain fDepartment Health Protection, National Institute for Health and Welfare, PO Box 95, FIN70701 Kuopio, Finland.

gDepartment of Public Health, University of Helsinki, Tukholmankatu 8B, P.O.Box 20, 00014 Helsinki, Finland.

hCIBER Respiratorio (CIBERES), Av. Monforte de Lemos, 3-5. Pabellón 11. Planta 0 28029, Madrid, Spain.

iDivision of Environmental Epidemiology, Institute for Risk Assessment Sciences (IRAS), Utrecht University, P.O. Box 80178, 3508 TD Utrecht, the Netherlands.

jNetherlands Institute for Health Services Research (NIVEL), Postbus 1568

3500 BN Utrecht, The Netherlands.

\begin{abstract}
We investigated the effect of weekends and school holidays on the daily frequency and severity of respiratory and other symptoms among children attending schools with (index) or without (reference) moisture damage in Spain, the Netherlands, and Finland. Throughout 1 year, parents of 419 children with a respiratory condition attending index $(n=15)$ or reference $(n=10)$ primary schools completed three symptom diaries. We assessed associations between lower respiratory tract, upper respiratory tract or allergy, and other symptom scores and school day, weekend, or summer holiday using mixed regression models stratified by country and moisture damage. We evaluated interactions between moisture damage and type of day. We combined country-specific estimates (incidence rate ratios [IRRs] and $95 \%$ confidence interval [CI]) in
\end{abstract}


Casas, L., Espinosa, A., Pekkanen, J., Asikainen, A., Borràs-Santos, A., Jacobs, J., Krop, E., Täubel, M., Hyvärinen, A., Heederik, D., Zock, J.P. School attendance and daily respiratory symptoms in children: influence of moisture damage. Indoor Air: 2016, 27(2), 303-310

meta-analyses. Symptom scores were lower during weekends and holiday. Lower respiratory tract symptoms were statistically significantly less common during holiday with strongest effect in index schools (IRR=0.7; CI=0.6-0.8). Reporting of other symptoms was more reduced during holiday in index (IRR=0.6; $C I=0.4-0.9)$ than in reference (IRR=0.95; $C I=0.8-1.2)$ schools (interaction $\mathrm{P}<.01$ ). In conclusion, symptoms were less frequent and/or severe during summer holiday and weekends. This pattern was stronger among children attending moisture-damaged schools, suggesting potential improvement in moisture damage-related symptoms during school breaks.

\section{PRACTICAL IMPLICATIONS}

Occupants of damp buildings are at increased risk of onset and exacerbation of asthma, respiratory infections, and allergic disorders. However, very little is known about the potential improvement effects of temporary exposure avoidance. We show that school holiday has positive effects on daily respiratory symptoms, among children with a respiratory condition. These effects are stronger among children attending moisture-damaged schools. This finding suggests potential improvement in symptoms related to moisture damage.

\section{INTRODUCTION}

Occupants of damp buildings are at increased risk of onset and exacerbation of asthma, respiratory infections, and allergic disorders.[1-5] Most previous studies focused on moisture damage at home, used self-administered questionnaires to assess dampness/mold, and had cross-sectional designs. To date, few studies have investigated health effects of moisture damage and dampness in schools.[6-10] Studies performed in Sweden and USA showed a higher prevalence of asthma or respiratory symptoms among workers and children attending schools with moisture damage. $[9,10]$ Two Finnish longitudinal studies investigated the effect of moisture damage repairs in schools on microbial conditions and pupils' respiratory symptoms. They concluded that full renovations of damaged schools reduced the concentrations of microbial agents and the prevalence of respiratory symptoms in children. $[\underline{8,11}]$ The HITEA project (Health Effects of Indoor Pollutants: Integrating microbial, Toxicological and Epidemiological Approaches)[12] investigated the respiratory and allergic health effects of school moisture damage in three European countries (Spain, the Netherlands, and Finland). Previously, we reported positive cross-sectional associations of moisture damage in schools with respiratory symptoms. [6,7] In the present analysis, we report longitudinal associations between daily respiratory symptoms and school attendance among school children with respiratory conditions attending schools with or without moisture damage. We compare the effect of school days, weekends, or summer school holidays on the daily presence and severity of respiratory and other symptoms between pupils of damaged and non-damaged schools. 
Casas, L., Espinosa, A., Pekkanen, J., Asikainen, A., Borràs-Santos, A., Jacobs, J., Krop, E., Täubel, M., Hyvärinen, A., Heederik, D., Zock, J.P. School attendance and daily respiratory symptoms in children: influence of moisture damage. Indoor Air: 2016, 27(2), 303-310

\section{METHODS}

\subsection{Study design and population}

As part of the HITEA project, 57 schools in Finland, the Netherlands, and Spain were selected for standardized building inspections. The inclusion criteria were willingness to participate, having more than 200 pupils and not having planned major repairs or renovations during the study period. Schools were classified as moisturedamaged (index) or non-damaged (reference) based on the number, extent, severity and location of dampness, and moisture damage observations recorded during the inspections. Two schools, one in Spain and one in the Netherlands, had two buildings, one with and one without moisture damage. In these schools, each building was considered as an independent school and classified in the index or reference group accordingly. Details on the selection and inspections are described elsewhere.[12]

During the fall of 2008, parents of pupils from the first to the sixth grades (i.e., third to eight grade in the Netherlands), aged 6-12 years, were invited to complete a baseline questionnaire that included the following information on respiratory conditions of their child: wheezing, dry cough at night and asthma medication in the last 12 months, ever asthma, and doctor-diagnosed asthma. Written informed consent was obtained from all participants, and the study was approved by the Ethics Committees in each region. During the winter of 2009, 15 index and 10 reference schools were selected for more detailed exposure and health characterization. Parents of children who were not in the highest school grades and who reported at least one of the five respiratory conditions in the baseline questionnaire were invited to fill out three symptom diaries: a 2-week diary starting before the summer school holiday (May-July 2009), a 3-week diary starting at the end of the summer holiday (AugustOctober 2009), and a 2-week diary during winter and spring (January-May 2010). From 433 children whose parents filled in at least 1 day in one diary, we included 419 children attending 25 schools: 8 schools and 106 children in Spain, 11 schools and 150 children in the Netherlands, and 6 schools and 163 children in Finland. We excluded children moving from index to reference buildings (or vice versa) across school years or without information on the school building. Furthermore, we excluded diaries which had recorded the same date for more than 1 day, and winter holiday days because of the low numbers (33 person-days). Our analyses included 16165 person-days (3626 person-days in Spain, 5840 person-days in the Netherlands, and 6699 person-days in Finland).

\subsection{Daily symptoms}

To assess the daily number and severity of respiratory and other symptoms, we used diaries developed in English and translated into Spanish, Catalan, Dutch, and Finnish. They were administered to the parents and included the following question: 'Did your child experience any of the following symptoms in the last 24 hours?', listing wheeze, shortness of breath, dry cough during day, dry cough at night, phlegm, woken up with breathing problems, runny or stuffed nose, dry or sore throat, hoarseness, red, swollen or itchy eyes, headache, fever, fatigue, and muscular pain. Each daily symptom was scored according to its severity (no symptom, slight, moderate, or severe).

Based on the type of symptom and the severity reported, we created three scores of groups of symptoms: lower respiratory tract, upper respiratory tract or allergy, and 
Casas, L., Espinosa, A., Pekkanen, J., Asikainen, A., Borràs-Santos, A., Jacobs, J., Krop, E., Täubel, M., Hyvärinen, A., Heederik, D., Zock, J.P. School attendance and daily respiratory symptoms in children: influence of moisture damage. Indoor Air: 2016, 27(2), 303-310

other symptoms. The lower respiratory tract symptom score included wheeze, shortness of breath, woken up with breathing problems, dry cough during day, dry cough during night, and phlegm. The upper respiratory tract or allergy symptom score included runny or stuffed nose, dry or sore throat, hoarseness, and red, swollen, or itchy eyes. The other symptom score included headache, fever, fatigue, and muscular pain. Severity was considered by assigning a value to each category linked to the specific symptom, ranging from 0 (no symptom) to 3 (severe). The score in each symptom group was equal to the sum of the severity scores given to each specific symptom in the group. Therefore, the score for lower respiratory symptoms that included six symptoms ranges from 0 to 18, and the scores for upper respiratory or allergy symptoms and other symptoms included four symptoms and range from 0 to 12 .

\subsection{School days, weekends, and holidays}

Based on the dates reported for each day in the diaries, the official school calendar in each country, and the day of the week, we created a three-category variable describing the type of day: school day, weekend (or <1-week holiday), and summer holiday. School days were official school days (Monday-Friday). Weekend (or $<1$ week holiday) were Saturdays, Sundays, or official school holidays that were not part of a block of seven consecutive holidays and weekend days. Summer holidays were defined as official country-specific school holidays between the 1st of June and the 30th of September that were part of a block of at least seven consecutive official school holidays and weekend days.

\subsection{Potential confounders}

The baseline questionnaire administered to the parents provided information on the age and sex of the child, the presence of mold at home, the country of origin of the parents, and education. In the diaries, a part from the symptoms, parents reported information on their child's daily exposure to tobacco smoke indoors ( $\geq 30$ minutes), and having a cold or a flu on that specific day.

\subsection{Statistical analyses}

We used chi-square tests to compare the distribution between pupils from damaged and non-damage schools. For description purposes, the three symptom scores were categorized into three categories: $0,1-2$, and $\geq 3$. In multivariable analyses, the scores were treated as continuous variables. To obtain adjusted incidence rate ratios (IRRs) and their $95 \%$ confidence intervals (CI) of the associations between the symptom scores and the type of day, we used multilevel negative binomial regression models allowing for overdispersion per country. School, diary (before/beginning of summer holiday, end of/after summer holiday, and winter/spring diary), and individual were included as random effects. Individual was nested within school and diary within individual. We used exchangeable covariance matrix to take into account the correlation within individuals and diaries. Age, sex, having a cold, and being exposed to smoke were included in the models as fixed effects. The models for Finland did not include exposure to smoke because it was only reported on 6 days. Models per country were (1) stratified by moisture damage at school, and (2) not stratified by moisture damage but included the interaction terms between moisture damage at school and type of day to assess effect modification of moisture damage. We used meta-analyses techniques to combine the adjusted country-specific estimates per moisture damage, and the interaction P-values from the non-stratified 
Casas, L., Espinosa, A., Pekkanen, J., Asikainen, A., Borràs-Santos, A., Jacobs, J., Krop, E., Täubel, M., Hyvärinen, A., Heederik, D., Zock, J.P. School attendance and daily respiratory symptoms in children: influence of moisture damage. Indoor Air: 2016, 27(2), 303-310

models. Heterogeneity was examined using the I-squared statistic. Data analysis was conducted with STATA SE 14.0 statistical software (Stata Corporation, College Station, TX, USA).

\section{RESULTS}

Statistically significant differences in child characteristics according to moisture damage exposure were only observed among Spanish children, where parental education was lower and the prevalence of asthma was higher among children attending index schools compared with reference schools (Table 1 ).

Table 2 describes the information collected in the diaries by country and moisture damage. Overall, more than half of the days included in the diaries were school days, one-quarter were weekends, and $18 \%$ were holiday days. However, the distribution was different across countries. In Spain, the percentage of holiday days was higher compared with the Netherlands and Finland. Regarding the report of having a cold, parents of Spanish children attending index schools reported less days of cold compared with those of children attending reference schools. In Spain and the Netherlands, the prevalence of days when the child was exposed to smoke was higher among children attending index schools. In Finland, exposure to smoke was reported on 6 days. Minimal differences between index and reference schools were observed for the symptom scores in the three countries.

\section{[TABLE 1]}

\section{[TABLE 2]}

Table $\underline{3}$ shows the adjusted associations between the type of day and the symptom scores by country and moisture damage, and the P-values for the interaction terms between moisture damage group and type of day. Generally, holiday and weekends were associated with lower scores. The IRRs were $<1$ and significant for the three scores and holiday among children attending index schools in Spain. In the Netherlands, the associations were only statistically significant among children attending reference schools. Holiday in Dutch reference schools was associated with less respiratory symptoms and weekends with other symptoms. In Finland, statistically significant associations were observed in index and reference schools for holiday with the three scores. Weekend was associated with significant reductions in upper respiratory or allergy symptoms in Spanish and Finnish reference schools, with significant reductions in other symptoms in Dutch reference schools, and with significant reductions in upper respiratory or allergy and other symptoms in Finnish index schools. In Spain and Finland, the IRRs for holiday was lower generally in index schools compared with reference schools. The P-value for the interaction between type of day and moisture damage group was below .05 for holiday and lower respiratory and other symptoms in Spain, and for other symptoms in Finland. Heterogeneity across countries was high for holiday and all scores, and for weekends and other symptoms in index schools (I2>80\%).

[table 3]

Table $\underline{4}$ shows that all random-effects combined IRRs were <1. In index schools, weekend was significantly associated with the scores for upper respiratory or allergy symptoms, and holiday with the scores for lower respiratory and other symptoms. In reference schools, the combined IRR was statistically significant for weekends and 
Casas, L., Espinosa, A., Pekkanen, J., Asikainen, A., Borràs-Santos, A., Jacobs, J., Krop, E., Täubel, M., Hyvärinen, A., Heederik, D., Zock, J.P. School attendance and daily respiratory symptoms in children: influence of moisture damage. Indoor Air: 2016, 27(2), 303-310

upper respiratory or allergy and other symptoms, and for summer holiday and lower respiratory symptoms. The combined P-values for the interaction between holiday and moisture damage were below .05 for other symptoms.

[table 4]

\section{DISCUSSION}

Our large multicenter study shows that children with a respiratory condition report less symptoms and/or less severe respiratory or other symptoms during weekends and summer holiday compared with school days. This effect is stronger during summer holiday than during weekends and, for lower respiratory and other symptoms, the effect is greater among children attending schools with moisture damage problems. This finding is suggestive of the possibility to improve adverse health effects on school days by correcting moisture damage or dampness problems in schools.

Previous studies reported increased prevalence of asthma exacerbations after summer school holidays.[13,14] They attributed the observed effect to factors that are more prevalent during fall (i.e., infectious, allergic, environmental, and climatic stimuli), to the stress of attending school, and to the indoor air quality in schools.[15] The school environment is a significant reservoir for several biological agents and other environmental factors that are related with the development of asthma and exacerbations.[16] Previous studies reported higher concentrations of allergens and endotoxins in schools compared with homes.[17-21] Furthermore, schools are usually located in areas where pickup and drop-off is easily performed by private cars and/or school buses. Therefore, the concentrations of traffic-related air pollutants in the school may be high. Moreover, ventilation and building maintenance in schools are, in many cases, poor and the crowdedness in the classrooms contributes to particle resuspensions.[22-25] This combination of factors that are specific for the school environment may explain our findings of less reported symptoms in school holidays and weekends, regardless of the presence of moisture damage in the school building.

Moisture damage in buildings is common and there is sufficient evidence that it has a negative impact on respiratory and allergic health.[4] Previously, we reported higher prevalence of respiratory and allergic symptoms among children attending index schools. [6, 7] The results of these studies are consistent with the few previous studies in school environments[8-10] and with our present findings. The mechanisms underlying the associations between moisture damage and respiratory health are not yet clear. Microbial agents, secondary metabolites produced by fungi and bacteria, volatile organic compounds, and allergens are more common in moisture-damaged buildings and have been proposed as potential agents that contribute to adverse health effects of moisture damage, dampness, and associated microbial growth. [2630] Yet, epidemiological studies including quantitative measures of microbial agents, species, and/or products rather than qualitative measures of moisture damage or dampness show inconclusive results.[4]

To date, the potential improvement effects of school holiday on symptoms related with moisture damage exposure at school have only been investigated among Finnish school workers. Consistent with our results, this study reported lower concentrations of inflammatory markers and respiratory and allergic symptoms after summer school holiday.[31] Furthermore, results from intervention studies where they compare the 
Casas, L., Espinosa, A., Pekkanen, J., Asikainen, A., Borràs-Santos, A., Jacobs, J., Krop, E., Täubel, M., Hyvärinen, A., Heederik, D., Zock, J.P. School attendance and daily respiratory symptoms in children: influence of moisture damage. Indoor Air: 2016, 27(2), 303-310

health status of occupants of moisture-damaged buildings before and after reparations were consistent with our findings. They showed reductions in the prevalence of respiratory symptoms and infections after full repairs among primary school children.[32]

A major limitation of intervention studies is that occupants are aware of the intervention and their responses regarding symptoms before and after the intervention may be biased. The observational nature of our study diminishes the effect of a potential reporting bias in comparison with intervention studies. However, we cannot exclude the possibility that parents of children attending index schools tend to report more, and also more severe symptoms during school days. This would result in an overestimation of the holiday effect among children attending index schools. Furthermore, parental perception of the severity of symptoms may be influenced by their stress during working days. This perception would also overestimate the effect of school holiday and weekends. In contrast, the presence of moisture damage at home may underestimate the effects of holiday or weekends. In our study, the prevalence of mold at home was low in Spain and Finland, and not different between index and reference schools. Moreover, additional adjustment for mold at home did not modify our results (data not shown). Biases due to parental perception of severity or to presence of mold at home would be equally present in schools with and without moisture damage and would not influence the differences between both groups.

Seasonal variations in respiratory symptoms may partly explain the effects of summer holiday.[13] Unfortunately, our study only included 33 days of winter holiday, all of them in the Netherlands. Because of the low numbers, we decided to exclude these days from the analyses. Nevertheless, we included weekends and $<1$ week holiday during all seasons and we observed similar trends for weekends and short holidays than those observed for summer holiday. Moreover, to account for seasonality, our models included diary (before/beginning of summer holiday, end of/after summer holiday, and winter/spring diary) as random effect and having a cold as fixed effect. Although a potential seasonal effect cannot be completely ruled out, the stronger effects observed for summer holiday compared with weekends may indicate a dose-response effect rather than a season effect. In any case, the potential seasonal effect does not explain the stronger effects of holiday among children attending index schools.

Moreover, we show geographical variation in the investigated effects. In Spain, we observed effects only in index schools. In the Netherlands, such effects were significant in reference schools. In Finland, the effects are observed in both groups, although they were stronger in the index schools. Consistently, previous crosssectional studies within the HITEA project showed that the effects of moisture damage were mainly observed in Finland.[7] Climate may explain the geographical differences observed. First, low relative humidity is linked with respiratory irritation.[33] We observed lower relative humidity in Finnish schools compared with the Dutch and Spanish schools.[6] Second, climate determines indoor microbial growth.[34-36] In the HITEA project, the levels of measured microbial markers in schools were higher in Spain and the Netherlands compared with Finland.[7, 37] In addition, ventilation in Finnish schools was mechanical, while that of Spanish and Dutch schools was most often natural.[12] The type of ventilation may also influence the sources of the indoor microbiome, with natural ventilation allowing the outdoor 
Casas, L., Espinosa, A., Pekkanen, J., Asikainen, A., Borràs-Santos, A., Jacobs, J., Krop, E., Täubel, M., Hyvärinen, A., Heederik, D., Zock, J.P. School attendance and daily respiratory symptoms in children: influence of moisture damage. Indoor Air: 2016, 27(2), 303-310

microbiome to penetrate in the school and, probably, reducing the indoor-outdoor differences in terms of microbial exposures.

Our study relies on a number of strengths that are worthwhile to highlight. We prospectively followed 419 children attending 25 schools in three geographically spread European countries during 1 year, which was translated into more than 16000 daily reports of symptoms spread throughout the year. These daily respiratory symptoms were scored not only according to the frequency but also to the severity, using standardized and recently validated diaries in the three countries.[38] In addition, the assessment of moisture damage in schools was not only based on the occupant reports and perceptions but on standardized inspections realized by trained researchers and supported by measures of microbial agents, species, and metabolites. In conclusion, we show that school holiday and weekends have effects on the frequency and severity of symptoms, among children with respiratory conditions. The effects are stronger during school holiday and among children attending moisture-damaged schools. This suggests that the school environment may be an important source of risk factors for acute symptoms during childhood, and emphasizes the relevance of moisture damage in schools buildings as risk factor for respiratory and other symptoms. This may have an impact on school attendance and, indirectly, on school performance.

\section{ACKNOWLEDGEMENTS}

This work was supported by the European Commission as part of HITEA (Health Effects of Indoor Pollutants: Integrating microbial, toxicological and epidemiological approaches), Grant agreement no. 211488 under the Seventh Framework Program, Topic ENV.2007.1.2.1.1. "Indoor air pollution in Europe: An emerging environmental health issue". We acknowledge all the parents, children, and schools participating in the HITEA-School study, in Spain, the Netherlands, and Finland as well as the field workers from the University Utrecht (the Netherlands), the Centre for Research in Environmental Epidemiology (Barcelona, Spain), and the National Institute for Health and Welfare (Kuopio, Finland).

\section{REFERENCES}

Arundel, A. V, Sterling, E.M., Biggin, J.H. and Sterling, T.D. (1986) Indirect health effects of relative humidity in indoor environments, Environ. Health Perspect., 65, 351-61. Benndorf, D., Müller, A., Bock, K., Manuwald, O., Herbarth, O. and von Bergen, M. (2008) Identification of spore allergens from the indoor mould Aspergillus versicolor, Allergy, 63, 454-460.

Bornehag, C.G., Sundell, J., Bonini, S., Custovic, A., Malmberg, P., Skerfving, S., Sigsgaard, T.

and Verhoeff, A. (2004) Dampness in buildings as a risk factor for health effects, EUROEXPO: a multidisciplinary review of the literature (1998-2000) on dampness and mite exposure in buildings and health effects, Indoor Air, 14, 243-57.

Borràs-Santos, A., Jacobs, J.H., Täubel, M., Haverinen-Shaughnessy, U., Krop, E.J.M., Huttunen, K., Hirvonen, M.-R., Pekkanen, J., Heederik, D.J.J., Zock, J.-P. and Hyvärinen, A. (2013) Dampness and mould in schools and respiratory symptoms in children: the HITEA study, Occup. Environ. Med., 70, 681-7.

Casas, L., Tischer, C., Wouters, I.M., Valkonen, M., Gehring, U., Doekes, G., Torrent, M., Pekkanen, J., Garcia-Esteban, R., Hyvärinen, a, Heinrich, J. and Sunyer, J. (2013) Endotoxin, extracellular polysaccharides, and $\beta$ (1-3)-glucan concentrations in dust and their determinants in four European birth cohorts: results from the HITEA project, Indoor Air, 23, 208-18. 
Casas, L., Espinosa, A., Pekkanen, J., Asikainen, A., Borràs-Santos, A., Jacobs, J., Krop, E., Täubel, M., Hyvärinen, A., Heederik, D., Zock, J.P. School attendance and daily respiratory symptoms in children: influence of moisture damage. Indoor Air: 2016, 27(2), 303-310

Chen, C.-M., Thiering, E., Doekes, G., Zock, J.-P., Bakolis, I., Norbäck, D., Sunyer, J., Villani,

S., Verlato, G., Täubel, M., Jarvis, D. and Heinrich, J. (2012) Geographical variation and the determinants of domestic endotoxin levels in mattress dust in Europe, Indoor Air, 22, 24-32. Claeson, A.-S., Nordin, S. and Sunesson, A.-L. (2009) Effects on perceived air quality and symptoms of exposure to microbially produced metabolites and compounds emitted from damp building materials, Indoor Air, 19, 102-112.

Cohen, H.A., Blau, H., Hoshen, M., Batat, E. and Balicer, R.D. (2014) Seasonality of asthma: a

retrospective population study, Pediatrics, 133, e923-32.

Fisk, W.J., Lei-Gomez, Q. and Mendell, M.J. (2007) Meta-analyses of the associations of respiratory health effects with dampness and mold in homes, Indoor Air, 17, 284-296.

Globe, G., Martin, M., Schatz, M., Wiklund, I., Lin, J., von Maltzahn, R. and Mattera, M.S. (2015) Symptoms and markers of symptom severity in asthma--content validity of the asthma symptom diary, Health Qual. Life Outcomes, 13, 21.

Godwin, C. and Batterman, S. (2007) Indoor air quality in Michigan schools, Indoor Air, 17, 109-21.

Haverinen-Shaughnessy, U., Borras-Santos, A., Turunen, M., Zock, J.-P., Jacobs, J., Krop, E.J.M., Casas, L., Shaughnessy, R., Täubel, M., Heederik, D., Hyvärinen, A., Pekkanen, J. and Nevalainen, A. (2012) Occurrence of moisture problems in schools in three countries from different climatic regions of Europe based on questionnaires and building inspections the HITEA study, Indoor Air.

Hirvonen, M.R., Ruotsalainen, M., Roponen, M., Hyvärinen, A., Husman, T., Kosma, V.M., Komulainen, H., Savolainen, K. and Nevalainen, A. (1999) Nitric oxide and proinflammatory cytokines in nasal lavage fluid associated with symptoms and exposure to moldy building microbes, Am. J. Respir. Crit. Care Med., 160, 1943-6.

Huffaker, M. and Phipatanakul, W. (2014) Introducing an environmental assessment and intervention program in inner-city schools., J. Allergy Clin. Immunol., 134, 1232-7.

IOM (2004) Damp Indoor Spaces and Health, Washington, DC, National Academies Press (US).

Jacobs, J.H., Krop, E.J.M., de Wind, S., Spithoven, J. and Heederik, D.J.J. (2013) Endotoxin levels in homes and classrooms of Dutch school children and respiratory health., Eur.

Respir. J., 42, 314-22.

Jacobs, J.H., Borràs-Santos, A., Krop, E., Täubel, M., Leppänen, H., Haverinen-

Shaughnessy, U.,

Pekkanen, J., Hyvärinen, A., Doekes, G., Zock, J.-P. and Heederik, D. (2014a) Dampness, bacterial and fungal components in dust in primary schools and respiratory health in schoolchildren across Europe, Occup. Environ. Med., 71, 704-12.

Jacobs, J.H., Krop, E.J.M., Borras-Santos, A., Zock, J.-P., Taubel, M., Hyvarinnen, A.,

Pekkanen, J., Doekes, G. and Heederik, D.J.J. (2014b) Endotoxin levels in settled airborne dust in European schools: the HITEA school study, Indoor Air, 24, 148-57.

Johnston, N.W. and Sears, M.R. (2006) Asthma exacerbations . 1: epidemiology., Thorax, 61 ,

722-8.

Krop, E.J.M., Jacobs, J.H., Sander, I., Raulf-Heimsoth, M. and Heederik, D.J.J. (2014)

Allergens

and $\beta$-glucans in dutch homes and schools: characterizing airborne levels, PLoS One, 9, e88871.

Lai, P.S., Sheehan, W.J., Gaffin, J.M., Petty, C.R., Coull, B.A., Gold, D.R. and Phipatanakul, W.

(2015) School endotoxin exposure and asthma morbidity in inner-city children., Chest, 148, 1251-8.

Lignell, U., Meklin, T., Putus, T., Rintala, H., Vepsäläinen, A., Kalliokoski, P. and Nevalainen, A. (2007) Effects of moisture damage and renovation on microbial conditions and pupils' health in two schools--a longitudinal analysis of five years, J. Environ. Monit., 9, 225-33. Lincoln, D., Morgan, G., Sheppeard, V., Jalaludin, B., Corbett, S. and Beard, J. (2006)

Childhood

asthma and return to school in Sydney, Australia, Public Health, 120, 854-62. 
Casas, L., Espinosa, A., Pekkanen, J., Asikainen, A., Borràs-Santos, A., Jacobs, J., Krop, E., Täubel, M., Hyvärinen, A., Heederik, D., Zock, J.P. School attendance and daily respiratory symptoms in children: influence of moisture damage. Indoor Air: 2016, 27(2), 303-310

Meklin, T., Potus, T., Pekkanen, J., Hyvärinen, A., Hirvonen, M.-R. and Nevalainen, A. (2005)

Effects of moisture-damage repairs on microbial exposure and symptoms in schoolchildren, Indoor Air, 15 Suppl 1, 40-7.

Mendell, M.J. and Heath, G.A. (2005) Do indoor pollutants and thermal conditions in schools influence student performance? A critical review of the literature, Indoor Air, 15, 27-52. Mendell, M.J., Mirer, A.G., Cheung, K., Tong, M. and Douwes, J. (2011) Respiratory and allergic health effects of dampness, mold, and dampness-related agents: a review of the epidemiologic evidence, Environ. Health Perspect., 119, 748-56.

Peitzsch, M., Sulyok, M., Täubel, M., Vishwanath, V., Krop, E., Borràs-Santos, A., Hyvärinen,

A., Nevalainen, A., Krska, R. and Larsson, L. (2012) Microbial secondary metabolites in school buildings inspected for moisture damage in Finland, The Netherlands and Spain, J. Environ. Monit. JEM, 14, 2044-2053.

Permaul, P., Hoffman, E., Fu, C., Sheehan, W., Baxi, S., Gaffin, J., Lane, J., Bailey, A., King, E.,

Chapman, M., Gold, D. and Phipatanakul, W. (2012) Allergens in urban schools and homes of children with asthma, Pediatr. Allergy Immunol., 23, 543-9.

Reponen, T., Lockey, J., Bernstein, D.I., Vesper, S.J., Levin, L., Khurana Hershey, G.K., Zheng,

S., Ryan, P., Grinshpun, S.A., Villareal, M. and Lemasters, G. (2012) Infant origins of childhood asthma associated with specific molds, J. Allergy Clin. Immunol., 130, 639644.e5.

Sahakian, N.M., White, S.K., Park, J.-H., Cox-Ganser, J.M. and Kreiss, K. (2008) Identification

of mold and dampness-associated respiratory morbidity in 2 schools: comparison of questionnaire survey responses to national data, J. Sch. Health, 78, 32-7.

Sauni, R., Verbeek, J.H., Uitti, J., Jauhiainen, M., Kreiss, K. and Sigsgaard, T. (2015)

Remediating buildings damaged by dampness and mould for preventing or reducing respiratory tract symptoms, infections and asthma, Cochrane database Syst. Rev., 2, CD007897.

Schlink, U., Thiem, A., Kohajda, T., Richter, M. and Strebel, K. (2010) Quantile regression of indoor air concentrations of volatile organic compounds (VOC), Sci. Total Environ., 408, 3840-3851.

Sheehan, W.J., Rangsithienchai, P.A., Muilenberg, M.L., Rogers, C.A., Lane, J.P., Ghaemghami,

J., Rivard, D. V., Otsu, K., Hoffman, E.B., Israel, E., Gold, D.R. and Phipatanakul, W. (2009) Mouse allergens in urban elementary schools and homes of children with asthma, Ann. Allergy, Asthma Immunol, 102, 125-130.

Smedje, G. and Norbäck, D. (2000) New ventilation systems at select schools in Sweden-effects

on asthma and exposure, Arch. Environ. Health, 55, 18-25.

Smedje, G., Norbäck, D. and Edling, C. (1997) Asthma among secondary schoolchildren in relation to the school environment, Clin. Exp. Allergy, 27, 1270-8.

Stranger, M., Potgieter-Vermaak, S.S. and Van Grieken, R. (2008) Characterization of indoor air

quality in primary schools in Antwerp, Belgium, Indoor Air, 18, 454-463.

Thorne, P.S., Cohn, R.D., Mav, D., Arbes, S.J. and Zeldin, D.C. (2009) Predictors of endotoxin

levels in U.S. housing, Environ. Health Perspect, 117, 763-771.

WHO (2009) WHO guidelines for indoor air quality: dampness and mould, Copenhagen, World

Health Organization. 